\title{
Multicultural Education in the US: Current Issues and Suggestions for Practical Implementations
}

\author{
Yahya Alghamdi, ${ }^{1, *}$ \\ ${ }^{1}$ Dept. of Curriculum \& Instructions and Literacy Development, Cleveland State University, \\ 2121 Euclid Avenue, Cleveland, OH 44115-2214, USA \\ *Correspondence: Dept. of Curriculum \& Instructions and Literacy Development, Cleveland \\ State University, 2121 Euclid Avenue, Cleveland, OH 44115-2214, USA. Tel: \\ 966-550-786-688 E-mail: y.a.alghamdi@vikes.csuohio.edu
}

Received: February 9, 2017

Accepted: April 14, 2017 Published: May 26, 2017

doi:10.5296/ije.v9i2.11316

URL: https://doi.org/10.5296/ije.v9i2.11316

\begin{abstract}
The purpose of this paper is to shed light on the concept of multiculturalism in educational settings in the US. Particularly, it discusses the term multicultural education as well as some of its advantages in education. Also, this paper presents an overview of the history and key dimensions of multicultural education in the US. In addition, it presents some of the current major issues and dilemmas of multicultural education that inhibit its effectiveness in many public schools around the US. Finally, this paper provides some practical suggestions and insights for an effective implementation of a multicultural education system.
\end{abstract}

Keywords: Multiculturalism, Multicultural Education, Immigration, Diversity, US Public School. 


\section{Introduction}

The United States of America (US) has been so far called "a melting-pot country" or a multicultural nation. This metaphor was given to reflect the country's accumulation of immigrants from different countries over history. Those immigrants found the US the most convenient destiny to seek work opportunities and a better and safe life. Immigration is one of the main reasons that made the US a diverse and a multicultural country. Because of immigration, schools around the country admit students every year from different racial and cultural backgrounds. Those diverse students need an educational system that addresses their needs and facilitate their learning.

Consequently, public schools in the US should consider the issue of multiculturalism in order to provide a quality-equity education and a democratic environment including social justice to all students who are less advantaged than their peers in the dominant society (Gollnick \& Chinn, 2013). In this paper, I will shed lights on multicultural education by considering its definition, importance, and advantages based on evidence and impact of its implementation. Additionally, I will discuss the origins, history, and dimensions of multicultural education. Furthermore, I will highlight some current dilemmas, concerns, and practices that are taking place regarding multicultural education. Finally, I will provide some possible recommendations for effective implementation of a multicultural education system.

\subsection{Definitions of Multicultural Education}

Multicultural education is an educational system that follows a standard process to deliver basic educational concepts that are suitable for all students. This system requires an overall school reformation to confront some practices of discrimination and racism in schools and communities. This reformation should target schools curricula and the strategies used in their teaching and the interactions between school personnel as well as students and their families (Lucas, 2010).

Diverse students who are seeking education in the US have different characteristics compared to their peers in the dominant society. These characteristics involve different physical and mental abilities, gender, ethnic and racial backgrounds, socioeconomic classes, languages, religions, and sexual orientations. Therefore, it is demanded to develop an educational system that addresses diversity.

Koppleman (2011) acknowledged that a multicultural education involves students with racial and ethnic differences_-Blacks and Whites - as well as students of various nationalities that have come to the US to acquire a quality education. Such an acknowledgment admits that we should not only determine students' differences as individuals but also to customize the curricula to meet their needs. Accordingly, a multicultural education system requires an effective consideration in order for diverse students to get an equivalent opportunity to achieve their academic success (Banks \& Banks 2009). 


\section{Historical Overview and Key Dimensions of Multicultural Education}

Several factors influenced the history of multicultural education in the U.S. Foremost is the revolution of the civil right movements in 1962 (Banks, 2013). During the 1960s and 1970s, African Americans demanded freedom, social justice, political, economic and educational rights that they disadvantaged over the history (Banks, 2013). Another factor is the increasing number of immigrants to the US due to poverty, wars, and persecution they had in the countries of origin. The majority of American cultural groups are American Indians, European Americans, Latino Americans, Asian Americans, African Americans, and other Pacific Islanders (Ameny-Dixon, 2004; Gay, 2004). Gollnick and Chinn (2013) argue that the reason why people who chose to immigrate to the US - as their destination - from different countries is to fulfill the demands, for example, freedom, that they failed to achieve in their home countries.

The US has provided an active economy that requires a growing labor force, which has matched some of those immigrants' willingness and ambitions. However, some who arrived as slaves, for example, the early Mexicans, who became residents after the US government has seized their lands, have not yet met the typical aspirations of immigrants and are still struggling within the socio-political and economic context of the U.S. (Gollnick \& Chinn, 2013).

Studies have shown that the number of immigrants over the last decades, who preferred the US as their destination, has been nearly one million per year (Monger \& Yankay, 2013). Four states including California, New York, Florida, and Texas embrace more than half of the foreigners who were born outside the US. This makes up one-fourth of California's population and one-fifth of New York's population (Gollnick \& Chinn, 2013). A recent study has shown that the number of foreign-born population in the US has increased dramatically, from 9.6 million in 1970 to 41.3 million in 2013 (Zong \& Batalova, 2015). This means that the number of immigrants has grown from 4.7 percent in 1970 to 13.1 percent in 2013 (Zong \& Batalova, 2015). These figures prove that the US is a multicultural country and, therefore, dictates that schools have diverse populations. Since the occurrence of the civil rights movement along with the increasing number of ethnic groups, all has made a need for an educational system that addresses multiculturalism.

As mentioned previously, the term multicultural education is a broad concept that has a variety of essential dimensions. Therefore, educators and school reformers should acknowledge this fact and understand these dimensions for a better integration of a multicultural education system (Banks, 2004).

Banks and Banks (2009) mentioned five key dimensions of a multicultural education system. The first dimension focuses on content integration, which refers to the extent to which educators will use examples and different sources from a variety of cultures in their curriculum when teaching students with diversity. Teachers might include different generalizations, principles, key concepts, and theories in their subject area or discipline. It makes diverse students feel that they are able to better understand how society adapts to the 
changes and how it is addressed in different ways (Banks \& Banks, 2009). Thus, teachers need to reflect students' different cultures in curriculum materials when teaching diverse students. For instance, teachers might link a classroom discussion to students' cultural practices and lifestyles in language arts or social studies classes by integrating multicultural stories in reading classes and ask students to share their voices when addressing such discussions. These strategies will create an environment of appreciation and respect among diverse students.

The knowledge construction process is another dimension, which emphasizes students to recognize, examine, and decide social norms, structure of references, views, and biases within self-control that may better influence their knowledge construction and transformation (Banks \& Banks, 2009; Banks, 1996). Teachers can use social studies to show their students the process of knowledge construction. For instance, a teacher may ask his students to explain "the war in the north" - a particular event in history. Of course, with the existence of students from different cultures in the classroom, those from the Middle East would explain that it is from Russia, and so forth. In this case, the role of the teacher is to acknowledge that there are diverse students in the class that belongs to different societies. Therefore, he or she should address the issue and explain per person what the prompt really means to them in relation to their different origins. In addition, teachers may ask their students to share their cultural stories like some kinds of practices they do in particular events or holidays.

The third dimension focuses on prejudice reduction, which aims to help and aid students in developing democratic racial attitudes that are positive in nature. Teachers should guide them to see the bright side of uniqueness, yet a part of a society that welcomes their uniqueness. Banks (2009) defined prejudice reduction as assisting students with classroom instructions so they can eliminate their intentions regarding others with diverse cultural backgrounds. In other words, teachers' goal is to create positive ethnic and racial attitudes among their students; simply by using images and country maps in their classrooms that explain different cultural groups may contribute to achieving this goal.

The fourth dimension focuses on equity pedagogy. Educators can practice this dimension by differentiating their teaching strategies to accommodate their students' academic achievement, even if they belong to different racial groups (Banks, 2009). Demonstrating this dimension requires teachers to include students' families and their cultural practices when teaching history classes. Above all, teachers should integrate a cooperative learning by gathering students in small groups. These groups require a mixture of students with different levels of performance and different cultural backgrounds so they can learn from each other and share different experiences. Consequently, teacher education programs should be more responsible for implementing training programs to educate pre-service and in-service teachers on how to teach in multicultural classrooms.

The final dimension focuses on empowering school culture and social structure. While it is true that many schools have students of different races and origins, the role of such organizations - including all staff members - is to promote equality among diverse students and contribute to its reformation (Banks, 2009). Grouping and labeling practices, 
participating in sports, reducing achievement gaps between groups, varieties in enrollment rates in gifted and special education programs, the participation of the staff and the students across ethnic and racial borders are essential variables that schools should inspect and restructure to create an engaging diverse society (Banks, 2009). Public schools may implement some sports activities that include a team of students from different grades playing against their school staff members. These practices may create an atmosphere of trust and intimacy between students and school members.

Multicultural education needs more insights and appreciations not only from schools but also from the society as to accept and support diversity in education. Banks (1996) concluded that all the five dimensions are correlated; therefore, schools should consistently focus on and give sufficient attention to all these dimensions in order to implement an effective multicultural system.

\section{Advantages of Implementing a Multicultural Educational System}

Many students from different countries and diverse cultural backgrounds came to the US to seek quality education. Students from the dominant culture should understand differences and similarities between their own culture and other cultural backgrounds. Implementing a multicultural education system has several advantages for future generations. First, it creates an engaging and socialization classroom climate, so it is important for teachers when delivering educational instructions to address students' cultural diversity. Second, it develops confidence and friendship between students and their teacher, which may increases students' performance. Therefore, teachers should show care and respect to their students' ethnic and racial backgrounds to achieve such goals (Gay, 2004). Furthermore, participating in classroom activities allow students to learn from each other by sharing different thoughts and ideas from different cultural experiences.

Consequently, multicultural education, if adopted effectively, will help in reducing racial attitudes among students and improving diverse students learning to achieve academic success so they can be active participants in the society (Okoye-Johnson, 2011). Finally, providing challenging activities to all students, for example, encouraging multicultural music in arts education, can promote their cognitive thinking skills and creativity (Reed, 2010). The role of teachers here is to add more efforts to ensure that all students are achieving these advantages. Hence, creating a multicultural classroom environment that addresses the previous strategies may narrow the achievement gap between students from the dominant society and others who came from diverse cultural backgrounds (Okoye-Johnson, 2011).

\section{Current Issues and Dilemmas of Multicultural Education in the US}

Many schools in the US undergo some dilemmas that impede an effective implementation of a multicultural education system. One of these dilemmas is the idea that different cultural groups should assimilate and neglect their cultural identities so they can be accepted by the 
dominant society (Ameny-Dixon, 2004). Additionally, some educational organizations fail to address diversity among their students. For example, Guild (2001) wrote that teachers and instructors always treat students as if they are all equal. They deliver the same instructional strategies, give the same test to measure all students' performance, always marginalize diversity, and only carry biases toward uniformity. These practices impede students' performance, especially minority students whose cultural backgrounds are different from that of the majority (Guild, 2001).

Educators should understand that students are different therefore should receive differentiated instructions to achieve the demands of No Child Left Behind Act and the American Dream. In this regard, Hochschild and Scovronick (2003) emphasized that public school students are capable of success as long as they have equal opportunities in education. On the other hand, Noguera (2003) noticed that whites are more likely to succeed in the American society compared to African Americans and other minorities at public schools. In addition, Kirkland (2013) has discussed the literacy of Black males through the lenses of social and cultural context. He mentioned that teachers should understand that "pleasure, play, curiosity, and creativity are prerequisites to literacy" (p. 8). However, "if schools teach the basics well, then there is no excuse for illiteracy" (Hochschild \& Scovronick, 2003, p. 10). All these practices have labeled schools around the US that serve poor and non-white students as failures (Noguera, 2003).

Another concern in multicultural education is that students of different cultural backgrounds and, particularly, poor students are presumed to be less knowledgeable and less competent to succeed in class participation and educational activities (Noguera, 2003). Kirkland (2013) describes how Black males were believed to be threatening, bad, and lacking literacy. He mentioned the story of a teacher and her young Black male in which she was surprised that her student's writing in his diary was totally different from what he writes in his class. He was always writing in his diary in an interesting way; however, he did not share it with his teacher. The labels and stereotypes of society, 'Blacks are inferior to Whites', caused this situation. The student did not trust his teacher well enough to share his writings, which then affected his work productivity in class (Kirkland, 2013).

The social context in urban areas, in which the population is a construction of impoverished-Blacks and minorities, is the main concern that confronts public schools (Bishaw, 2014). Miretzky and Stevens (2012) mentioned that millions of black male and female students go to low-performing schools around the country that have teachers who lack training in dealing with multicultural education. Therefore, such issues have contributed to increase the achievement gap between students who go to public schools in American major cities compared to students in other schools that are comprised of only Whites (Noguera, 2003).

\section{Suggestions for Effective Implementation of a Multicultural Education System}

Issues of conflictions in a multicultural society remain pervasive in many public schools 
around the US. For this reason, there is a litany of recommendations and different types of approaches to consider when implementing an engaging multicultural education system to help diverse learners improve their academic achievement.

First, having professional and diverse teachers to teach students in public schools around the country that serve minority and diverse students is mandatory. Gollnick and Chinn (2013) emphasized on hiring faculty members who are qualified and trained to deal with diverse learners. Thus, the role of teachers is inevitable in empowering and enhancing schools that serve diverse learners.

Second, effective implementation of a multicultural education system requires public schools to have some characteristics and qualities that contribute to students' academic success. For instance, schools need to establishing classrooms that are equipped with modern technology to support cooperative learning, having recreation rooms for students to spend their leisure breaks, and other extra facilities that help visitors to engage in the school activities. Additionally, teachers should implement differentiated and effective instructional strategies that address multiple intelligences to meet diverse learners needs and increase their motivation (Danzi, Reul, \& Smith, 2008).

Third, the implementations of teacher education programs that prepare pre-service teachers for a multicultural education system have started since 1981 (Cochran-Smith, 2003). Hence, teacher education departments should be aligned with school reform policies to provide teachers with training programs that enable them to create an environment that values a multicultural education system. These institutions are also responsible to enhance in-service teachers with training programs that promote their awareness of multicultural education (Gay \& Howard, 2000).

Fourth, The role of schools, being as social institutions, is to encourage diverse social groups of different races to form their own unions and organizations, grant them with the same rights as the other groups, and enable them to excel in various activities. In order to create such unions, schools should implement different programs to engage students and their families in cultural activities that promote and reinforce social ties among other cultural groups.

Last but not least, school environments should be portrayed with reciprocal understanding and respect to students who have characteristics that are different from other students in the dominant culture. Teachers should also make sure that these differences should not stand as obstacles to hinder their students' rights in education. In addition, it is suggested to implement a multicultural curriculum that includes lessons of students' history, experiences, and cultural traditions so that all students in the classroom are able to know and understand diverse groups in their country (Gollnick \& Chinn, 2013).

\section{Conclusion}

The concept of multicultural education is too broad; therefore, teachers should understand that delivering basic educational concepts that are suitable for all students is a significant part 
due to different characteristics their students have. The importance of implementing multicultural education has many advantages that all students should gain to be active participants in the society. The history of this concept has evolved since the civil rights movement and constant immigration to the country, which, therefore, made schools receiving diverse populations from different countries. Educators should understand and adhere to the five key dimensions of multicultural education and give up all different practices that hinder its implementation. Eventually, schools as social institutions should encourage diverse social groups to form their own unions and organizations, implement engaging activities and programs that would help narrowing the achievement gaps between diverse learners, promote solidarity, teamwork and morality.

\section{References}

Ameny-Dixon, G. M. (2004). Why multicultural education is more important in higher education now than ever: A global perspective. International Journal of Scholarly Academic Intellectual Diversity, 8(1), 1-9.

Banks, J. A. (Ed.). (1996). Multicultural education, transformative knowledge and action. New York: Teachers College Press.

Banks, J. A. (2004). Multicultural education: Historical development, dimensions, and practice. In J. A. Banks \& C. A. M. Banks (Eds.), Handbook of Research on Multicultural Education (2nd ed.), (pp. 484-497). San Francisco, CA: Joosy-Bass.

Banks, J. A., \& Banks, C. A. M. (2009). Multicultural education: Issues and perspectives. John Wiley \& Sons, Inc.

Banks, J. A. (2013). The construction and historical development of multicultural education, 1962-2012. Theory Into Practice, 52(sup1), 73-82. https://doi.org/10.1080/00405841.2013.795444

Bishaw, A. (2014). Changes in areas with concentrated poverty: 2000 to 2010. American Community Survey Reports.

Cochran-Smith, M. (2003). Standing at the crossroads: Multicultural teacher education at the beginning of the 21st century. Multicultural Perspectives, 5(3), 3-11. https://doi.org/10.1207/S15327892MCP0503_02

Danzi, J., Reul, K., \& Smith, R. (2008). Improving student motivation in mixed ability classrooms using differentiated instruction. Online Submission.

Gay, G., \& Howard, T. C. (2000). Multicultural teacher education for the 21 st century. The Teacher Educator, 36(1), 1-16. https://doi.org/10.1080/08878730009555246

Gay, G. (2004). The importance of multicultural education. Educational Leadership, 61(4), 30-35. 
Gollnick, D. M., \& Chinn, P. C. (2013). Multicultural education in a pluralistic society. Pearson Higher Ed.

Guild, P. B. (2001). Diversity, learning style and culture. New Horizons for Learning. Retrieved April 9, 2015 from http://www.newhorizons.org/strategies/styles/guild.htm

Hochschild, J., \& Scovronick, N. (2003). The American dream and the public schools. New York, NY: Oxford University Press.

Kirkland, D. E. (2013). A search past silence: The literacy of young black men. Teachers College Press.

Koppelman, K. (2011). The great diversity debate: Embracing pluralism in school and society. Teachers College Press.

Lucas, A. G. (2010). Distinguishing between multicultural and global education: The challenge of conceptualizing and addressing the two fields. Clearing House, 83(6), 211-216. https://doi.org/10.1080/00098650903505373

Miretzky, D., \& Stevens, S. (2012). How does location impact meaning and opportunity? Rural schools and the NCATE diversity standard. Teachers College Record, 114(5), $1-36$.

Monger, R., \& Yankay, J. (2013). U.S. Legal permanent residents: 2010. Washington, D.C: U.S. Department of Homeland Security, Office of Immigration Statistics.

Noguera, P. (2003). City schools and the American dream: Reclaiming the promise of public education. New York: Teachers College Press.

Okoye-Johnson, O. (2011). Does multicultural education improve students' racial attitudes? Implications for closing the achievement gap. Journal Of Black Studies, 42(8), 1252-1274. https://doi.org/10.1177/0021934711408901

Reed, M. T. (2010). Multicultural music: A partner for 21st century skills. Illinois Music Educator, 71(2), 94-95.

Zong, J., \& Batalova, J. (2015). Frequently requested statistics on immigrants and immigration in the United States. Retrieved March 7, 2015, from http://www.migrationpolicy.org/article/frequently-requested-statistics-immigrants-and-i mmigration-united-states

\section{Copyright Disclaimer}

Copyright for this article is retained by the author(s), with first publication rights granted to the journal.

This is an open-access article distributed under the terms and conditions of the Creative Commons Attribution license (http://creativecommons.org/licenses/by/3.0/). 